\title{
Research of furniture design based on Chinese traditional sustainable ideology
}

\author{
Lulu Chai ${ }^{*}$, Xiang Wang ${ }^{2}$, Zixuan Chen ${ }^{3}$ \\ ${ }^{1}$ School of Architecture and Art, North China University of Technology, Beijing, 100144, China \\ ${ }^{2}$ School of Architecture and Art, North China University of Technology, Beijing,100144, China \\ ${ }^{3}$ School of Architecture and Art, North China University of Technology, Beijing, 100144, China
}

\begin{abstract}
In recent years, the problems of environmental pollution and resource shortage have increased year by year, and the topic of sustainable development has aroused widespread concern. The simple sustainable ideas in Chinese traditional culture have made important contributions to the harmonious coexistence between people and nature in ancient China. By analyzing China's simple sustainable ideas, the author discovered the holistic view in the idea of 'Nature and Humanity', the frugal view of the 'Using wisely' idea, the concept of benevolence in the thought of 'love of all people and all things', the ecological view in the thought of 'things are not endless' and the view of life in the thought of 'Taoism follows nature', these five perspectives provide systematic sustainable ideas for modern furniture. This article will analyze these five ideas, combined with the development of contemporary society and the development of modern sustainable ideas, looking back on the current status of modern furniture design, so as to explore the specific application of modern furniture design under the simple sustainable ideas and provide new ideas for the sustainable design of modern furniture.
\end{abstract}

\section{Introduction}

At the end of the last century, the rapid development of industry and technology drove the continuous improvement of people's living and consumption levels, the speed of furniture replacement was accelerated and among the replaced furniture, $60 \%$ are wood furniture, so the demand for wood is increasing year by year. China's wood resource consumption demand reaches an average of 240 million $\mathrm{m}^{3}$ every year, the domestic resource supply can only reach 120 million $\mathrm{m}^{3}$, the gap between supply and demand has doubled, as a result, China ranks first in the world in terms of timber imports. At the same time, since a piece of furniture is usually eliminated after five to eight years, a lot of garbage will be produced. In China, about 85 million $\mathrm{m}^{3}$ of solid waste is produced every year, mainly composed of old wooden furniture. In response, the government has made corresponding countermeasures and promulgated and implemented some laws and national standards such as the Environmental Protection Law of the People 's Republic of China, the Energy Conservation Law, the Renewable Energy Law, the Circular Economy Promotion Law and standardize the efficient use of waste wood material resources to reduce ecological damage. In recent years, the sustainable development began to climax. In fact, China has begun to have a knowledge of nature since the middle and late paleolithic age, which laid a foundation for the simple sustainable ideas.
Fu Xi used gossip to express the law of changes in all things, and guided people to carry out human activities according to the laws of nature. In the pre-qin period, Taoists put forward the thought of 'doing nothing' to the king and rest and recuperate according to the laws of nature, thus making the country peaceful and the people safe. These simple sustainable ideas reflect the ancient people's survival ideas and lifestyle, contain the ancient people's philosophy of dealing with the relationship between humans and nature, play a guiding and enlightening role in modern sustainability, and provide inspiration and design methods for modern furniture design.

\section{Thought and Methods}

China's simple sustainable ideas can be roughly divided into five categories, 'Nature and Humanity', 'Using wisely', 'love of all people and all things', 'things are not the endless' and 'Taoism follows nature'. These ideas are not only reflected in people's lives, but also widely used in the field of design.

\subsection{The thought of 'Nature and Humanity'}

The idea of 'Nature and Humanity' holds that nature and human beings share the same root and are brothers and exist as a whole. The holistic view of the 'harmony between people and nature' in Fu Xi's gossip is the ancient people's preliminary understanding of the

* Corresponding author: Email: 1162041044@qq.com 
relationship between nature and humanity. During the warring states period, Zhuangzi believed that 'heaven and earth were born together with me, and all things were one with me'. In the Western Han Dynasty, Dong Zhongshu believed that heaven, earth, and people are the origin of all things and these are like hands and feet, and are indispensable. The ancients used the idea of 'Nature and Humanity' to maintain the harmony between man and nature. The holistic view of the 'Nature and Humanity' warns current people that man and nature are in a whole state and their destiny is connected, and require people to take nature into consideration when carrying out human activities.

The holistic view of man and nature in the 'Nature and Humanity' is also reflected in the design field. For example, Li Yu's two window frame designs cleverly integrate human needs and natural resources. The first

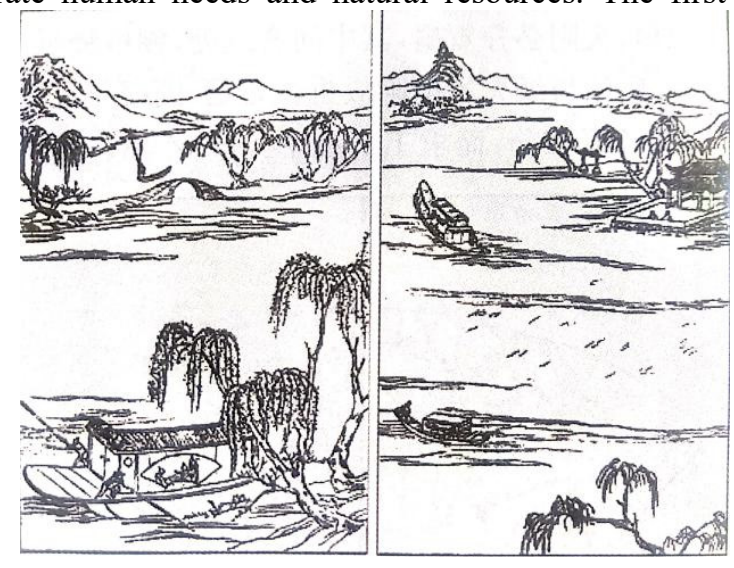

Figure 1. window design of cruise ship

Inspired by the idea of 'Nature and Humanity', the furniture industry should adjust the proportion of materials used, reduce the use of materials that may cause irreversible harm to the environment, increase the proportion of sustainable materials used, and promote harmony between man and nature.

\subsection{The thought of 'using wisely'}

'Using Wisely' means that the ancestors found the relationship between human society and nature, and the thought of advocating frugality. During the Spring and Autumn Period, Confucianism suggested that the king should put frugality on national policy; Taoism advocates reducing selfish desires, putting self and nature on the same position, and doing a good job of coordinating the relationship between man and nature; The Mohists talked about thrift and the rise and fall of the country; the Legalists linked thrift and blessing and misfortune, and believed that thrift can bring happiness. Schools promote frugality from different angles. In fact, they are essentially exhorting people to control their selfish desires within the range of natural tolerance and adjust the balance between humans and nature.

The idea of 'Using Wisely' is reflected in daily life, that is, it requires people to reduce unnecessary expenditures so that each item can be used to the maximum extent. The frugal concept of 'Using Wisely' window frame design is to open window holes on the left and right sides of the cruise ship, and make a fan-shaped frame with wood (Figure 1). Using the method of borrowing scenery, the natural scenery on both sides of the strait becomes a painting in the window frame. It not only meets the needs of people for lighting, ventilation and decoration, but also does no harm to the natural environment. The second design is that he used several dead woods as interior window frames to retain the original shape of the dead woods, cut the red paper into a flower shape, and adorned the branches, thus forming a scene of plum blossoms (Figure 2). Whether it is the method of borrowing scenery or the imagination of scenery, it is to process natural resources in the most harmless way to meet people's needs, so that nature and human needs are perfectly combined.

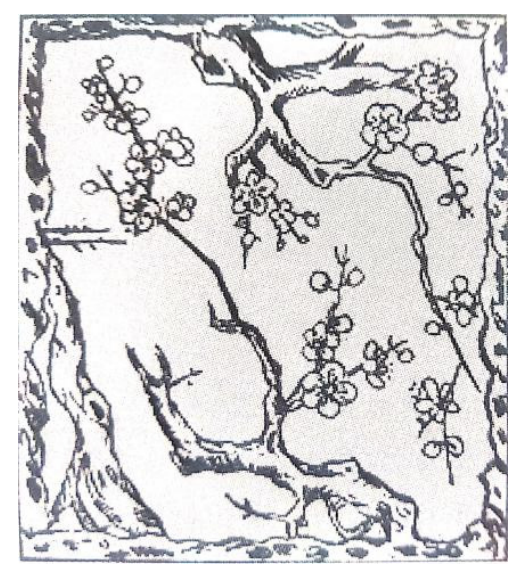

Figure 2. flower window design

puts forward two requirements for modern furniture: one is that the furniture structure should be multi-functional, detachable adjustment on furniture structure and reduce the duplication of non-essential furniture; the other is to reduce the consumption of packaging materials, transportation and storage costs on furniture packaging.

\subsection{The thought of 'love of all people and all things'}

The idea of 'love of all people and all things' is put forward by Zhang Zai in the Northern Song Dynasty. Its main idea is that all people are my brothers and sisters, all things are my companions, and people and things are born in heaven and earth. These ideas express that we should care for others and all things in nature with a heart of 'kindness'. The three major schools of thought of Confucianism, Buddhism and Taoism all have similar expressions.

Confucianism mainly regards the thought of 'benevolence' as the core. People of benevolence and morality should regard all things in the world and themselves as one, and loving all things should be like loving themselves. Taoism is based on the view that humans and things have equal status. People believe that humans are only one kind of everything. They are the same as other species. They are born in heaven and earth. they should be equal with all things and care for each 
other. The Buddhism regards compassion as its bosom. It emphasizes the preciousness of life and perceives the suffering of other things in a way of empathy, thus achieving the purpose of cherishing all things like cherishing oneself. Whether it is the Confucian view of 'benevolence', the Taoist view of 'equality', or the Buddhist view of 'compassion', all three believe that people should cherish everything in the world and not trample on it.

Allowing the objects around you to be used for a long time is also an expression of cherishing all things. When designing items, we should consider the ruggedness of the items.Modern furniture also needs to improve the durability of the product in terms of materials and structure, thereby increasing the life of the furniture. In addition to this, it is also necessary to understand the lifestyle and aesthetics of consumers during design, so as to improve the utilization rate of items and reduce the occurrence of discarded items.

\subsection{The thought of 'things are not endless'}

In view of ecological balance, the ancients put forward the idea of 'things are not endless', which means that when natural resources are used, it should not hurt the root of the things, should not exterminate its species, and should not cause irreparable damage to resources and species. In this regard, Confucius advocated not fishing with nets and not shooting resting birds in the nest. Mencius suggested that the king make laws that prohibit the burning of fields and the killing of animals in the spring and summer of all things. In Taoism, this idea is called 'knowledge', that is, knowing what is appropriate is enough. Lao Tzu believes that all catastrophes and disasters are caused by the expansion of human desire, which overwhelms the reasonableness. Knowing that it is enough, you can avoid danger and ensure long-term security. Both Confucianism and Taoism warn people to meet their basic needs when accessing natural resources, so as not to burden the ecological environment beyond the limits of self-recovery, and do not cause the extinction of species or other disasters.

In modern times, the continuous improvement of people's understanding of natural resources and the improvement of production technology have made the extraction of natural resources more convenient, but at the same time, the habitats of some species have been polluted, leaving the species in extinction or on the verge of extinction. In the process of furniture design, the problem of pollutants generated during material mining and furniture manufacturing and the impact of the energy used on nature must be considered.

\subsection{The thought of 'Taoism follows nature'}

The thought of 'Taoism follows nature' is based on the idea of 'Nature and Humanity' and takes the law of nature as the law of action, and finally reaches the state of conforming to the law of nature and living in harmony with heaven and earth. The word 'Taoism follows nature' comes from Laotse's Tao Te Ching, which refers to the law of natural development as 'Tao'. He believes that human beings should follow the law of natural development. With the conditions and characteristics of the matter, you can achieve twice the result with half the effort. On the contrary, without knowing the laws of nature, mischief will inevitably cause disasters. Zhuang $\mathrm{Zi}$ also stressed that we should not destroy the law of natural development because of the excessive behavior of human beings, but we should respect the law of development of things to carry out human activities and try our best to adjust the harmony of nature.

In ancient times, people used the characteristics of things to transform waste. An old monk built the wall with leftovers. The shapes and sizes of the leftovers are different, so that this wall has the momentum of a cliff. Although this is trivial things in life, the useless waste has been reused and a new destination has been found, and the circulation of things has been achieved. This is the application of 'Taoism follows nature' in real life. In today's life, human pollution and waste have also become more complicated. To truly realize the 'Taoism follows nature' ideas, people must consider the recycling and recycling of non-degradable parts.

These five ideological concepts have shown the ancient people's understanding and thinking of the harmonious coexistence of man and nature from different angles, and formed a simple sustainable ideas in China's traditional culture. These ideas are applied to modern furniture, which forms the theoretical basis of modern sustainable furniture design.

\section{Specific implementation in the design process}

China's simple sustainable thinking has an impact on the four stages of material selection, development and design, manufacturing, and disposal of modern furniture design. The choice of materials is mainly influenced by the idea of 'Nature and Humanity'; The development and manufacturing stage is mainly inspired by the ideas of 'Using Wisely' and 'love of all people and all things'; the production and manufacturing stage should be guided by the idea of 'things are not endless'; the disposal should follow the idea of 'Taoism follows nature'(Figure 3).

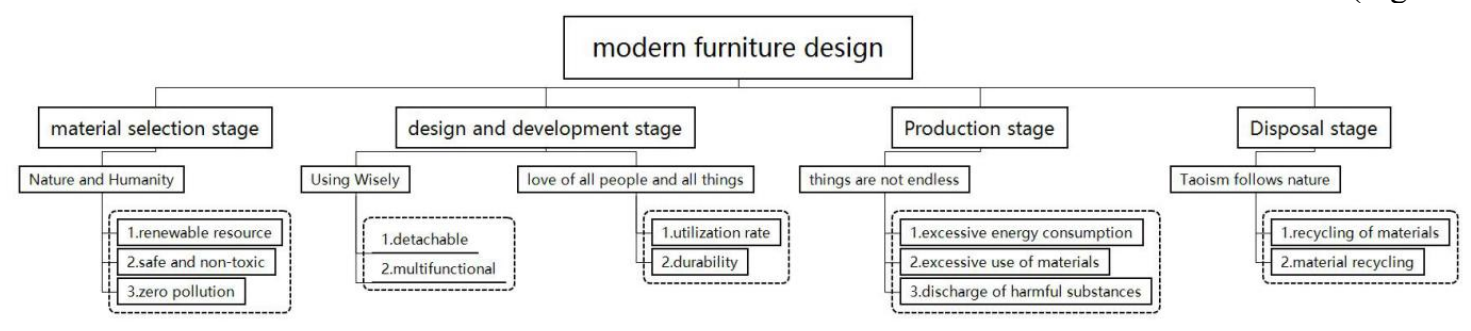

Figure 3. four stages of modern furniture design 


\section{1 material selection stage}

The materials of modern furniture in China are mainly composed of plastic, metal and wood, supplemented by bamboo, rattan, paper and other materials. Plastic is widely used because of its durability, strong moldability and low cost. However, it is non-renewable and non-degradable, and plasticizers will be transferred to the air and soil during the incineration of plastic products, causing environmental damage. Metal materials are strong, tough and ductile, suitable for mechanized production, but in the process of metal smelting, in addition to the high coal consumption, the large amount of carbon dioxide, sulfur oxides and nitrogen oxides produced will have a serious impact on the atmosphere. Although plastics and metals are easy to use and mass-produce, they have irreversible harm to the environment, so large-scale use is not recommended.

Bamboo and rattan have a short growth cycle. They have strong plasticity, and many processing methods. They are durable. they can achieve plant degradation and they can almost achieve zero pollution to the environment. Paper is a new type of furniture material, its recovery rate is $85 \%$, and it can be used repeatedly 8-10 times. Paper has a wide range of raw materials and can be made from fiber extracted from wood, wheat straw, reeds, sugar cane and other plants. Paper is easily degraded, safe and non-toxic. Straw has a wide source, it has a large output, and it is degradable and it has zero pollution. It can be processed into straw chipboard for furniture, and can also be used for surface decoration of furniture or directly stacked to make furniture.

Table1. Sustainable materials

\begin{tabular}{|l|l|l|l|l|}
\hline & \multicolumn{1}{|c|}{ Growth Cycle } & \multicolumn{1}{|c|}{ Character } & Process Mode & Environmental Protection \\
\hline Bamboo & 2 years & strong plasticity, many processing methods & plant degradation & almost achieve zero pollution \\
\hline rattan & $3-5$ years & strong plasticity, many processing methods & plant degradation & almost achieve zero pollution \\
\hline Paper & wide range of raw materials & $85 \%$ recovery rate & repeatedly $8-10$ times & safe and non-toxic \\
\hline Straw & large output & many processing methods & plant degradation & almost achieve zero pollution \\
\hline
\end{tabular}

Under the guidance of the 'Nature and Humanity', people recommend that the furniture industry use bamboo, rattan, paper, straw and fast-growing forest(Table1). Because the characteristics of each material are different, people should choose the appropriate material according to the quality of the material.

\section{2 design and development stage}

The design and development stage is the core stage in the entire process. It is the most detailed and comprehensive stage for designers to consider. At this stage, we need to consider the two ideas of 'using wisely' and 'love of all people and all things'.

The idea of 'using wisely' puts forward requirements on the structure and packaging of modern furniture. The structure of the furniture should be multifunctional and detachable. Multifunctional furniture can achieve the maximum value of the furniture's function, so that people can buy fewer kinds of furniture. From the perspective of supply and demand, multifunctional furniture can alleviate the crisis of shortage of furniture material resources. In furniture packaging, we should be streamlined, the most representative is flat packaging. Flat packaging is the most effective packaging material, which can reduce the waste of packaging materials. It is easy to place during transportation and manpower during transportation by loading more goods in the same space.

The idea of 'love of all people and all things' requires optimizing the lifespan of furniture in terms of utilization rate and durability, so that people cherish every item.

If you want to increase the utilization rate of furniture, people should understand the lifestyle and aesthetic culture of modern people. Intelligence and technology are gradually entering people's lives, and people's lives are more convenient. Today's aesthetic trends can be roughly divided into three types, popularization and diversification, perceptualization, and expression of cultural heritage.

The durability of furniture includes material durability and structural durability. Material durability refers to choosing durable materials and reducing the use of materials that are prone to corrosion, oxidation, and damage. Structural durability needs to consider safety and stability.At this stage, furniture designers need to repeatedly consider and experiment to meet the durability requirements.

\subsection{Production stage}

In the stage of furniture production and manufacturing, the behaviors that may violate the idea of 'things are not endless' can be divided into the following three categories:

The first point is excessive energy consumption. Excessive energy consumption will cause a large amount of pollutant emissions and cause atmospheric pollution and global warming. In February 2019, Australia announced that coral naked-tailed mice were extinct due to global warming and their habitats were submerged.

The second point is the excessive use of materials. The waste of scraps will increase the disposal of garbage and cause unnecessary energy consumption. At present, wood consumption ranks first in the consumption of furniture materials. If people increase material consumption, it means that more vegetation will be 
destroyed, the living environment of more species will be damaged, and the possibility of species extinction will increase.

The third point is the discharge of harmful substances. On January 2, 2020, the Chinese Academy of Fishery Sciences announced that the Yangtze white sturgeon was extinct, and the deterioration of the water environment was an important reason. In the process of processing wooden furniture, chemicals such as wood stains, glues, polishes, and solvents such as ethanol, ketones, and fragrances are used. These substances will produce organic compounds and toxic metals during using and drying. These toxic metals enter the rivers and lakes through the water system, causing pollution to the water environment.

The idea of 'things are not endless' is the last line of defense to protect the ecological environment. The extinction of a large number of species will inevitably affect the biological chain and ultimately affect humans. Therefore, this stage should attract the attention of the furniture industry.

\subsection{Disposal stage}

An excellent product manufacturer should consider the disposal of waste furniture materials and parts so that its product chain forms a closed loop. The conditions for forming a closed loop must be based on the laws of nature. This is the 'Taoism follows nature' thought in traditional Chinese culture. The waste disposal methods are divided into the following two types:

The first point is the recycling of materials. Material recycling refers to the effective conversion of waste according to natural laws. This method is also mentioned in the 'cradle to cradle' concept, people can refer to it.

The second point is material recycling. Material recycling can be divided into parts recycling and material recycling. Parts recycling is to repair and reuse the parts on the old furniture, which can reduce the manufacturing process and the use of parts materials. Material recycling is to reuse the main materials of waste furniture after extracting useful substances.

The idea of 'Taoism follows nature' is the wisdom of mankind to learn nature. Reducing the generation of garbage in a reasonable way is conducive to the harmonious coexistence of mankind and nature.

\section{Conclusion}

The five ideological concepts of 'Nature and Humanity', 'using wisely', 'love of all people and all things', 'things are not endless', and 'Taoism follows nature' run through the entire process of furniture. They embody the coexistence of humanity and nature. These simple sustainable ideas provide systematic theoretical ideas for the design of sustainable furniture, and leave a lot of inspiration for designers.

\section{Acknowledgements}

This paper is funded by the education project of North
China University of Technology in 2020, and is one of the phased achievements of Research and Experiment on Innovation and Entrepreneurship Education for Design College Students(215051360020XN156).

\section{References}

1. Zhang,Z. (2006) Steel manufacturing and environmental protection. J,Shanxi metallurgical:100-101

2. Zhao,Y. Wang,X.Zhang,Y. (2017) Application of straw material in modern furniture design. J, Furniture and interior decoration, 220:121-122.

3. Lu,L. (2011) Research on sustainable development of wooden furniture products. C, Nanjing forestry university.

4. Du,S. (2014) Sketches of Idle Pleasure. Zhonghua Book Company Publishing, Beijing.

5. Hu,M. Wang,Y. (2010) Moderation --The unique attitude of Confucianism towards nature. J, Social Sciences in Ningxia, No.159: 117-119

6. Zhang,H.Yin,G (2019) From content to method -enlightenment of ecological civilization education from laozi's Tao Te Ching . J, Journal of Mianyang Normal University, No.250,48-52+85.

7. Zhang, H.Yin, G. (2019) From Content to Method: The Enlightenment of Ecological Civilization Education in Lao Zi's "Dao De Jing" [J] .Journal of Mianyang Normal University, v.38; No.250,48-52 + 85.

8. Zhao, X. (2000) Confucianism and sustainable development [J] .Henan Social Sciences, 64-67. 